\title{
Article \\ Adiponectin Promotes VEGF Expression in Rheumatoid Arthritis Synovial Fibroblasts and Induces Endothelial Progenitor Cell Angiogenesis by Inhibiting miR-106a-5p
}

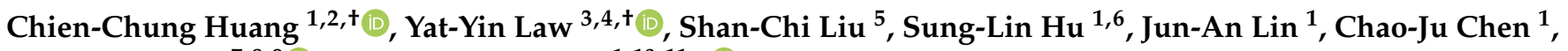 \\ Shih-Wei Wang $7,8,9$ (D) and Chih-Hsin Tang 1,10,11,*(D)
}

check for updates

Citation: Huang, C.-C.; Law, Y.-Y.; Liu, S.-C.; Hu, S.-L.; Lin, J.-A.; Chen, C.-J.; Wang, S.-W.; Tang, C.-H. Adiponectin Promotes VEGF

Expression in Rheumatoid Arthritis Synovial Fibroblasts and Induces Endothelial Progenitor Cell Angiogenesis by Inhibiting miR-106a-5p. Cells 2021, 10, 2627. https://doi.org/10.3390/cells10102627

Academic Editor: Yasmina Juarranz

Received: 19 August 2021

Accepted: 28 September 2021

Published: 1 October 2021

Publisher's Note: MDPI stays neutral with regard to jurisdictional claims in published maps and institutional affiliations.

Copyright: (c) 2021 by the authors. Licensee MDPI, Basel, Switzerland. This article is an open access article distributed under the terms and conditions of the Creative Commons Attribution (CC BY) license (https:/ / creativecommons.org/licenses/by/ $4.0 /)$.
1 School of Medicine, China Medical University, Taichung 40402, Taiwan; u104054003@cmu.edu.tw (C.-C.H.); d13437@mail.cmuh.org.tw (S.-L.H.); mqmarkrk@gmail.com (J.-A.L.); monkichi931210@gmail.com (C.-J.C.)

2 Division of Immunology and Rheumatology, Department of Internal Medicine, China Medical University Hospital, Taichung 40402, Taiwan

3 Institute of Medicine, Chung Shan Medical University, Taichung 40201, Taiwan; andrew.andrewlaw@gmail.com

4 Department of Orthopedics, Chung Shan Medical University Hospital, Taichung 40201, Taiwan

5 Department of Medical Education and Research, China Medical University Beigang Hospital, Yunlin 65152, Taiwan; sdsaw.tw@yahoo.com.tw

6 Department of Family Medicine, China Medical University Hsinchu Hospital, Hsinchu 30210, Taiwan

7 Department of Medicine, MacKay Medical College, New Taipei City 25245, Taiwan; shihwei@mmc.edu.tw

8 Graduate Institute of Natural Products, College of Pharmacy, Kaohsiung Medical University, Kaohsiung 80708, Taiwan

9 Institute of Biomedical Sciences, Mackay Medical College, New Taipei City 25245, Taiwan

10 Chinese Medicine Research Center, China Medical University, Taichung 40402, Taiwan

11 Department of Biotechnology, College of Health Science, Asia University, Taichung 40402, Taiwan

* Correspondence: chtang@mail.cmu.edu.tw; Tel.: +886-4-22052121 (ext. 7726); Fax: +886-4-22333641

+ Equal contribution.

Abstract: Rheumatoid arthritis (RA) is an erosive polyarthritis that can lead to severe joint destruction and painful disability if left untreated. Angiogenesis, a critical pathogenic mechanism in RA, attracts inflammatory leukocytes into the synovium, which promotes production of proinflammatory cytokines and destructive proteases. Adipokines, inflammatory mediators secreted by adipose tissue, also contribute to the pathophysiology of RA. The most abundant serum adipokine is adiponectin, which demonstrates proinflammatory effects in RA, although the mechanisms linking adiponectin and angiogenic manifestations of RA are not well understood. Our investigations with the human MH7A synovial cell line have revealed that adiponectin dose- and time-dependently increases vascular endothelial growth factor (VEGF) expression, stimulating endothelial progenitor cell (EPC) tube formation and migration. These adiponectin-induced angiogenic activities were facilitated by MEK/ERK signaling. In vivo experiments confirmed adiponectin-induced downregulation of microRNA-106a-5p (miR-106a-5p). Inhibiting adiponectin reduced joint swelling, bone destruction, and angiogenic marker expression in collagen-induced arthritis (CIA) mice. Our evidence suggests that targeting adiponectin has therapeutic potential for patients with RA. Clinical investigations are needed.

Keywords: adiponectin; rheumatoid arthritis; angiogenesis; VEGF; miR-106a-5p

\section{Introduction}

As a chronic autoimmune condition, rheumatoid arthritis (RA) is marked by symmetric destructive polyarthritis and systemic comorbidities [1]. The attraction of circulating leukocytes into the affected RA joints requires new blood vessels to supply the hypertrophic synovial membrane that is capable of invading the adjacent cartilage and causing bone erosions [2]. Angiogenesis is promoted by proinflammatory cytokines and significant 
angiogenic factors [3]. The inhibition of synovial angiogenesis is an appealing potential treatment strategy in RA, and avastin, the biologic that targets vascular endothelial growth factor (VEGF), has demonstrated therapeutic effects in type II collagen-induced arthritis (CIA) [4].

Adiponectin, the most abundant of all adipokines, is secreted by adipocyte tissue [5]. Adiponectin activates the AMPK and PPAR- $\alpha$ signaling pathways to regulate glucose and fatty acid metabolism [6]. It is also becoming clear that adiponectin is an important contributor to chronic inflammation, as is seen in cardiovascular disease, osteoarthritis (OA), the metabolic syndrome, and also RA [7]. Elevated levels of adiponectin have been found in human samples of RA serum and synovial fluid [8,9], while other research has determined that it is possible to predict radiographic joint damage from baseline serum adiponectin values in RA patients, and it is also established that adiponectin stimulates the production of interleukin (IL)-6, prostaglandin E2, and MMP in RA synovial fibroblasts [10,11]. However, the effect of adiponectin on RA angiogenesis is unclear. Adiponectin reportedly induces the production of VEGF in RA synovial fibroblasts and osteoblasts [12-14], and increases the expression of the inflammatory indicator endocan in RA synovial fibroblasts [15]. Cultured circulating endothelial progenitor cells (EPCs) can enhance blood vessel formation and have been used to induce angiogenesis and vascular repair under experimental conditions [16,17]. Previous reports have described elevated levels of EPCs in the RA synovial tissue [18], while enhanced late-outgrowth circulating EPC levels correlate positively with RA severity [19]. Research is needed to determine how exactly adiponectin mediates EPC-dependent angiogenesis in RA.

The short noncoding RNAs, microRNAs (miRNAs), post-transcriptionally modulate gene manifestations [20]. Various miRNA genes expressed in immune, inflammatory, and synovial cells from patients with RA [21] can cause synovial hyperplasia and bone damage, or promote inflammation, through positive or negative manipulation [22]. MiRNAs play crucial roles in adiponectin-associated metabolic syndrome, diabetes mellitus, fatty liver, and several cancers [23-26]. However, evidence is lacking as to miRNA activity during adiponectin treatment in RA. Our research has shown that adiponectin stimulates VEGF-dependent angiogenesis in RA synovial fibroblasts via MEK/ERK signaling and by downregulating miRNA-106a-5p (miR-106a-5p) expression. Inhibition of adiponectin significantly mitigated paw swelling, erosion of bone, and angiogenesis in the CIA mouse model. Taken together, the results help to clarify how adiponectin enhances angiogenic activity in inflamed joints of RA and suggest that an anti-angiogenic strategy targeting adiponectin would be beneficial for this disease.

\section{Materials and Methods}

\subsection{Cell Culture}

The MH7A cell line (human RA synovial fibroblasts) was obtained from Riken (Ibaraki, Japan) and the cell culture conditions were maintained according to established procedures [27,28]. Experiments were performed using $5 \times 10^{6}$ cells from passages 3 to 9 .

Human endothelial progenitor cells (EPCs) were prepared according to our previous protocols [29,30], after we obtained approval from the Institutional Review Board (IRB) of Mackay Medical College, New Taipei City, Taiwan (reference number: P1000002). Peripheral blood $(80 \mathrm{~mL})$ was collected from healthy donors after they completed written informed consent forms. Mononuclear cells $\left(3 \times 10^{7}\right.$ cells) were isolated from blood components by centrifugation on Ficoll-Paque PLUS (Amersham Biosciences, Uppala, Sweden). EPCs were maintained and characterized as follows: briefly, EPCs were seeded on gelatin-coated dishes containing MV2 medium, SupplementMix (PromoCell, Heidelberg, Germany), and 20\% nonheat-inactivated defined fetal bovine serum (FBS; HyClone, Logan, UT, USA). EPCs were characterized with $\mathrm{CD} 4^{+} / \mathrm{CD} 133^{+} / \mathrm{VEGFR}^{+}$antibodies using a FACSCalibur flowcytometer and CellQuest software (BD Biosciences, San Jose, CA, USA) [31]. 


\section{2. qRT-PCR Gene Expression Analysis of $m R N A$ and miRNA}

TRIzol reagent (Invitrogen, Waltham, MA, USA) was used to extract MH7A RNA. Subsequently, miRNA was detected according to the manufacturer's instructions of the Mir-XTM miRNA First Strand Synthesis Kit (Applied Biosystems, Foster City, CA, USA). We performed qPCR analysis according to an established protocol [32,33].

\subsection{Western Blot Analysis}

MH7A cells $\left(5 \times 10^{5}\right.$ cells $)$ were seeded into 6-well plates. Cell lysate was collected and separated as previously described [34,35]. All specific primary antibodies: anti-VEGF antibody (A17877; Abclonal, MA, USA), $\beta$-actin (SC-47778), p-MEK (SC-271914), MEK (SC-6250), p-ERK (SC-7383), and ERK (SC-1647) antibodies (Santa Cruz biotechnology, Dallas, TX, USA) were used for $24 \mathrm{~h}$. The densities of specific bands were visualized by chemiluminescence (ECL) reagents (WBKLS0500, Millipore Corp., Billerica, MA, USA).

\subsection{Enzyme-Linked Immunosorbent Assay (ELISA)}

The specific VEGF-A ELISA kits (DY293B; R\&D, Minneapolis, MN, USA) were used to measure the VEGF levels in conditioned medium. MH7A cells were transfected with specific adiponectin shRNA plasmids (National RNAi Core Facility, Taipei, Taiwan) and respective siRNAs (Dharmacon, Lafayette, CO, USA), or treated with specific inhibitors of PD98059 (P215) and U0126 (U120) (Sigma-Aldrich, St. Louis, MO, USA), then incubated with adiponectin. The conditioned medium was collected according to the manufacturer's instructions [36].

\subsection{EPC Tube Formation}

Tube formation was analyzed, as previously described [37]. Matrigel (BD Biosciences, Bedford, MA, USA) was coated onto 48-well plates and EPCs $\left(2 \times 10^{4}\right.$ per $\left.100 \mu \mathrm{L}\right)$ were resuspended in MV2 serum-free medium with the indicated adiponectin concentration for $24 \mathrm{~h}$, then added to the wells. After $12 \mathrm{~h}$ of incubation at $37^{\circ} \mathrm{C}$, EPC tube formation was assessed with a photomicroscope, and each well was photographed at $200 \times$ magnification. EPC tube formation was subjected to quantitative analysis software (ImageJ softwell).

\subsection{Transwell Migration Assay}

The Transwell migration assay was conducted, as previously described [37]. The number of cells per field of view was calculated using a Nikon ECLIPSE TS100 imaging optical microscope.

\subsection{Plasmid Construction and Luciferase Assay}

The wild type VEGF 3 '-UTRs with miR-106a-5p binding sites were inserted into the pmirGLO luciferase reporter vector (Promega, Madison, WI, USA). The mutant VEGF $3^{\prime}$ UTR region (MT-VEGF-3'-UTR) was obtained from Invitrogen (Waltham, MA, USA). Finally, luciferase activity was determined using a dual-luciferase reporter assay system (Promega, Madison, WI, USA).

\subsection{The Chick Chorioallantoic Membrane (CAM) Assay}

The CAM assay evaluated in vivo angiogenic activity, as previously described [38]. Angiogenesis activities were detected by microscopy and digital photographs.

\subsection{In Vivo Matrigel Plug Assay}

The protocol was performed as previously described [39]. Immunofluorescent staining was performed using anti-VEGF, anti-CD31, anti-CD34 (Abcam, Cambridge, MA, USA), and anti-CD133 (Biorbyt, Cambridge, MA, USA). 


\subsection{Collagen-Induced Arthritis Mouse Model}

The emulsion contained bovine type II collagen (CII, Chondrex, Redmond, WA, USA) and IFA Freund's incomplete adjuvant (Sigma-Aldrich. St. Louis, MO, USA) intradermally injected into each mouse tail root on day 0 , and we intra-articularly injected the same amount at day 14, according to the approved method [40].

Arthritis in CIA mice reliably develops within 6 weeks, and more than $90 \%$ of the mice will develop severe arthritis. Following both immunizations, the mice were allocated to the Control $(n=8)$, CIA $(n=8)$, and adiponectin shRNA $(n=8)$ groups. The mice received intraarticular injections with lentiviral adiponectin shRNA and sacrificed on day 56 of treatment. Paw swelling was measured in a blinded manner with a plethysmometer (Marsap, Mumbai, India) once weekly for 4 weeks to determine the clinical severity of arthritis. The tissues between ankle and phalangeal joints were prepared for micro-computed tomography (micro-CT) examinations.

\subsection{Ethics Statement}

All experiments involving human clinical samples were approved by the Institutional Review Board of China Medical University Hospital, which granted approval for this study to proceed (Approval no. CMUH108-REC3-039). All experiments involving animals were conducted according to the ethical policies and procedures issued by the Institutional Animal Care and Use Committee of China Medical University, which approved our experiments (Approval no. 2018-102).

\subsection{Statistical Analysis}

All results were analyzed using GraphPad Prism version 5.0 (GraphPad Software, Inc., La Jolla, CA, USA) and all values are expressed as the mean \pm S.D. Differences between selected pairs from the experimental groups were analyzed for statistical significance by the paired sample $t$-test. The statistical difference was regarded as significant when the $p$ value was $<0.05$.

\section{Results}

\subsection{Adiponectin Increases VEGF-Dependent EPC Angiogenesis in MH7A Cells}

First, to understand the association between adiponectin and EPCs in RA, we examined whether adiponectin stimulates EPC functions in MH7A cells. Adiponectin treatment of MH7A cells concentration- and time-dependently upregulated VEGF mRNA and protein expression (Figures $1 \mathrm{~A}-\mathrm{C}$ and $2 \mathrm{~A}-\mathrm{C}$ ). Incubating EPCs in culture medium from adiponectin-treated synovial fibroblasts concentration- and time-dependently upregulated EPC tube formation and migration activities. Adding VEGF monoclonal antibody decreased adiponectin-dependent tube formation and migration activities (Figures 1D,E and 2D,E). These results indicate that adiponectin induces EPC angiogenesis via VEGF upregulation in MH7A cells.

\subsection{MEK/ERK Signaling Is Critical for Adiponectin-Dependent EPC Angiogenesis}

The MEK/ERK signaling pathway has been regarded as important in adiponectin regulating cell functions [41-43]. We therefore checked the involvement of MEK/ERK signaling in adiponectin-enhanced VEGF production and angiogenesis. Incubating MH7A cells with adiponectin time-dependently increased MEK and ERK phosphorylation (Figures 3E and 4E). We then pretreated MH7A cells with MEK inhibitors (PD98059, U0126), an ERK inhibitor (ERK II), or transfected the cells with MEK or ERK siRNAs. The results showed that both MEK/ERK inhibitors and siRNAs reduce adiponectin-induced VEGF secretion (Figures $3 \mathrm{~A}, \mathrm{~B}$ and $4 \mathrm{~A}, \mathrm{~B}$ ). The effects of adiponectin on EPC angiogenic activities were also abolished (Figures 3C,D and 4C,D). Thus, adiponectin enhances VEGF expression and EPC angiogenesis in MH7A cells via MEK/ERK signaling. 
(A)

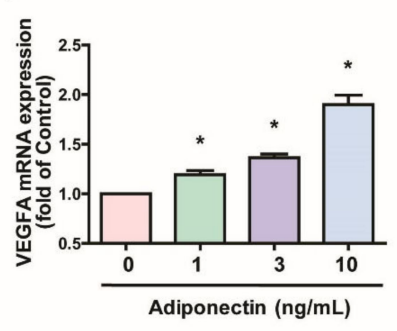

(D)

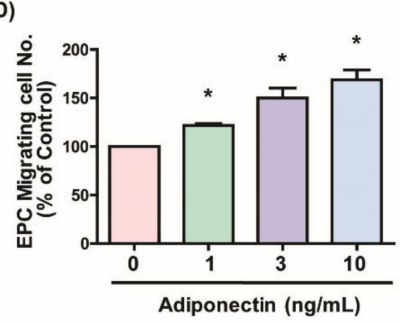

(B)

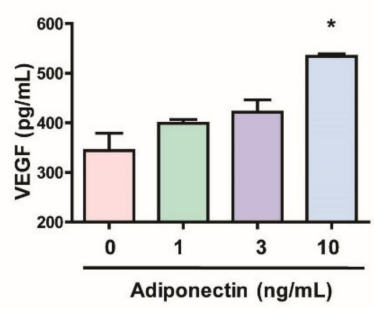

(E)

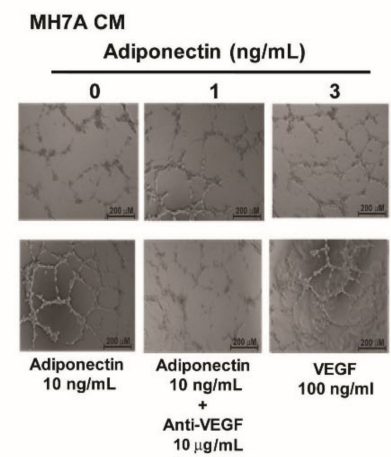

(C)
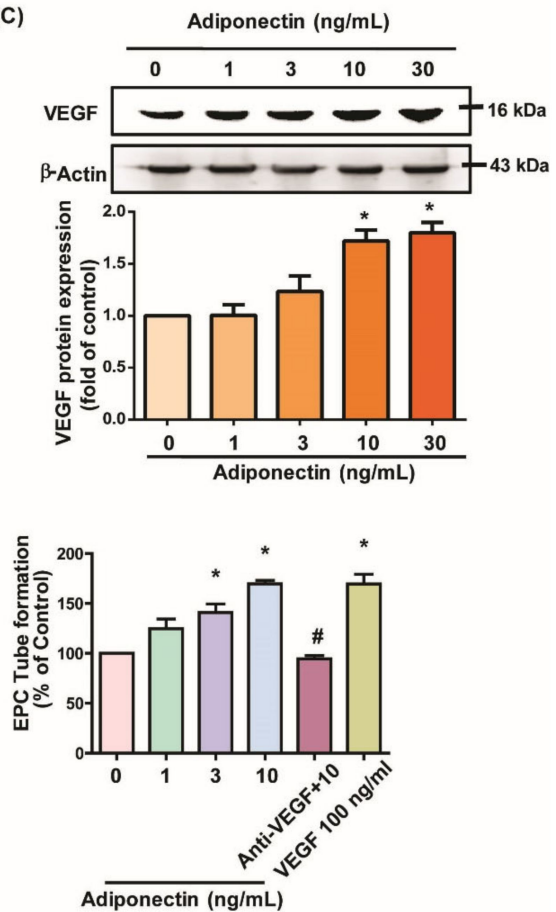

Figure 1. Adiponectin stimulates VEGF expression in MH7A cells and promotes EPC angiogenesis. (A-C) MH7A cells were treated with prespecified concentrations of adiponectin $(0-10 \mathrm{ng} / \mathrm{mL})$ for $24 \mathrm{~h}$. VEGF expression was examined by qPCR, ELISA, and Western blotting ( $n=4$ per group). (D,E) MH7A cells were treated with adiponectin $(0-10 \mathrm{ng} / \mathrm{mL})$ or pretreated with $30 \mathrm{~min}$ with VEGF antibody for $30 \mathrm{~min}$ then stimulated with adiponectin $(10 \mathrm{ng} / \mathrm{mL})$ for $24 \mathrm{~h}$. Medium was collected as CM; $200 \mu \mathrm{L}$ of $20 \%$ FBS MV2 medium and $150 \mu \mathrm{L}$ of MH7A CM was applied to the EPCs. Capillary-like structure formation and in vitro cell migration in EPCs were examined by the Transwell and tube formation assays. Direct application of VEGF (100 ng/mL) served as the positive control in EPC tube formation and migration ( $n=5$ per group). ${ }^{*} p<0.05$ versus the control group; ${ }^{*} p<0.05$ versus the adiponectin-treated group.
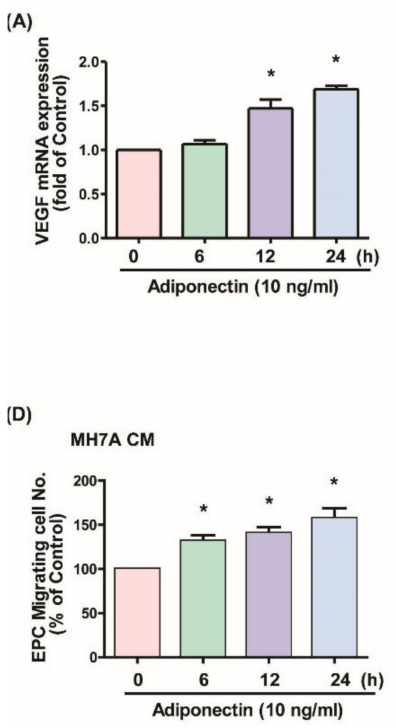

(B)

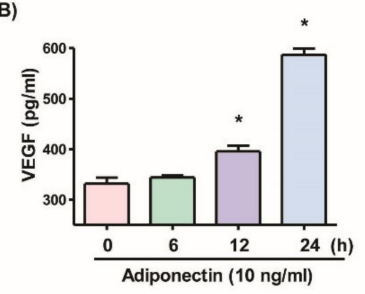

(E)

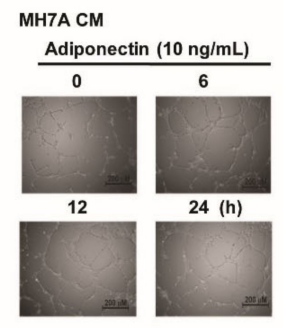

(C)

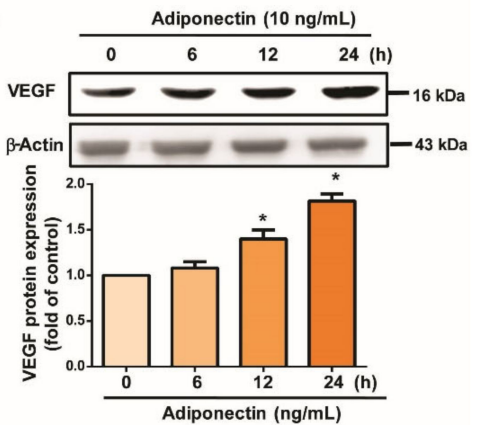

Figure 2. Adiponectin time-dependently enhances VEGF production in MH7A cells and EPC angiogenesis. (A-C) MH7A cells were treated with adiponectin $(10 \mathrm{ng} / \mathrm{mL})$ for 6,12 , and $24 \mathrm{~h}$. VEGF expression was examined by qPCR, ELISA, and Western blotting ( $n=4$ per group). (D,E) MH7A cells were treated with adiponectin $(10 \mathrm{ng} / \mathrm{mL})$ for 6,12 , and $24 \mathrm{~h}$. Medium was collected as CM; $200 \mu \mathrm{L}$ of $20 \%$ FBS MV2 medium and $150 \mu \mathrm{L}$ of MH7A CM was applied to the EPCs. Capillary-like structure formation and in vitro cell migration in EPCs were examined by the Transwell and tube formation assays $(n=5$ per group). ${ }^{*} p<0.05$ versus the control group. 


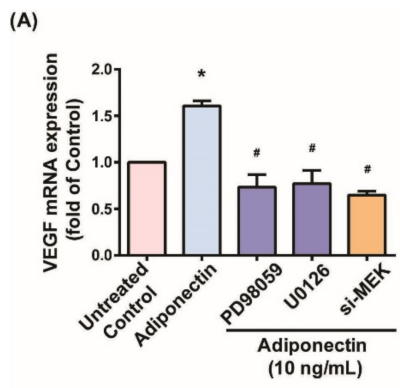

(B)

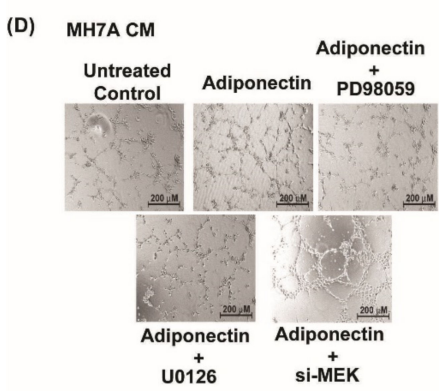

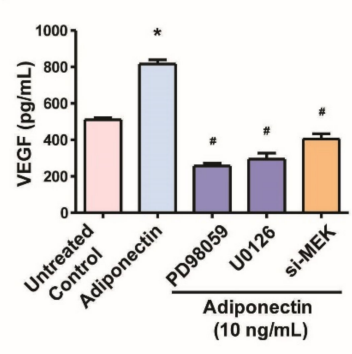

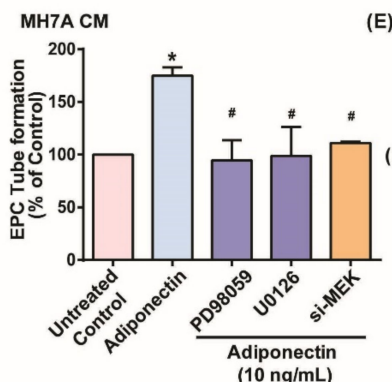

(C)

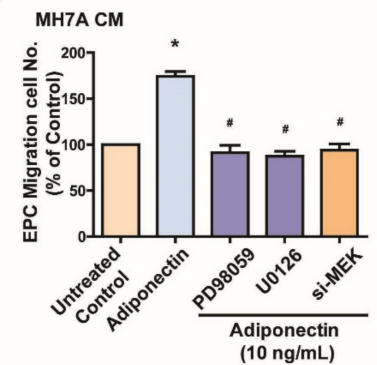

(E)
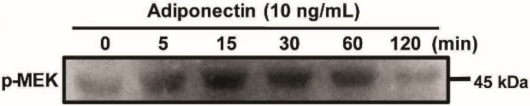

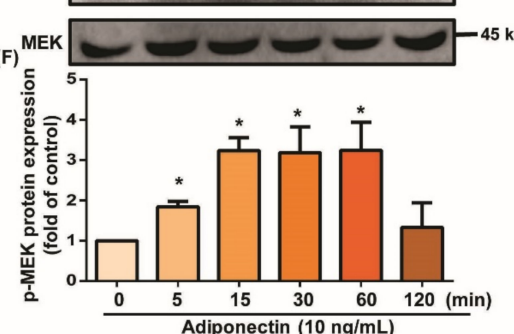

Figure 3. The MEK signaling pathway is required in adiponectin-induced EPC migration and tube formation. (A,B) MH7A cells were left untreated, stimulated with adiponectin $(10 \mathrm{ng} / \mathrm{mL})$ alone for $24 \mathrm{~h}$, or pretreated with MEK inhibitors (PD98059 and U0126) or transfected with MEK siRNA for $30 \mathrm{~min}$, prior to $24 \mathrm{~h}$ of adiponectin $(10 \mathrm{ng} / \mathrm{mL}) \mathrm{stimulation}$. VEGF expression was examined by qPCR and ELISA assays ( $n=4$ per group). (C,D) Collected CM from MH7A was applied to EPCs and angiogenesis was examined by the Transwell and tube formation assays ( $n=5$ per group). (E) MH7A cells were treated with adiponectin for varying amounts of time and Western blot $(n=3)$ determined MEK phosphorylation. (F) Densitometry analysis of (E). ${ }^{*} p<0.05$ versus the control group; ${ }^{\#} p<0.05$ versus the adiponectin-treated group.
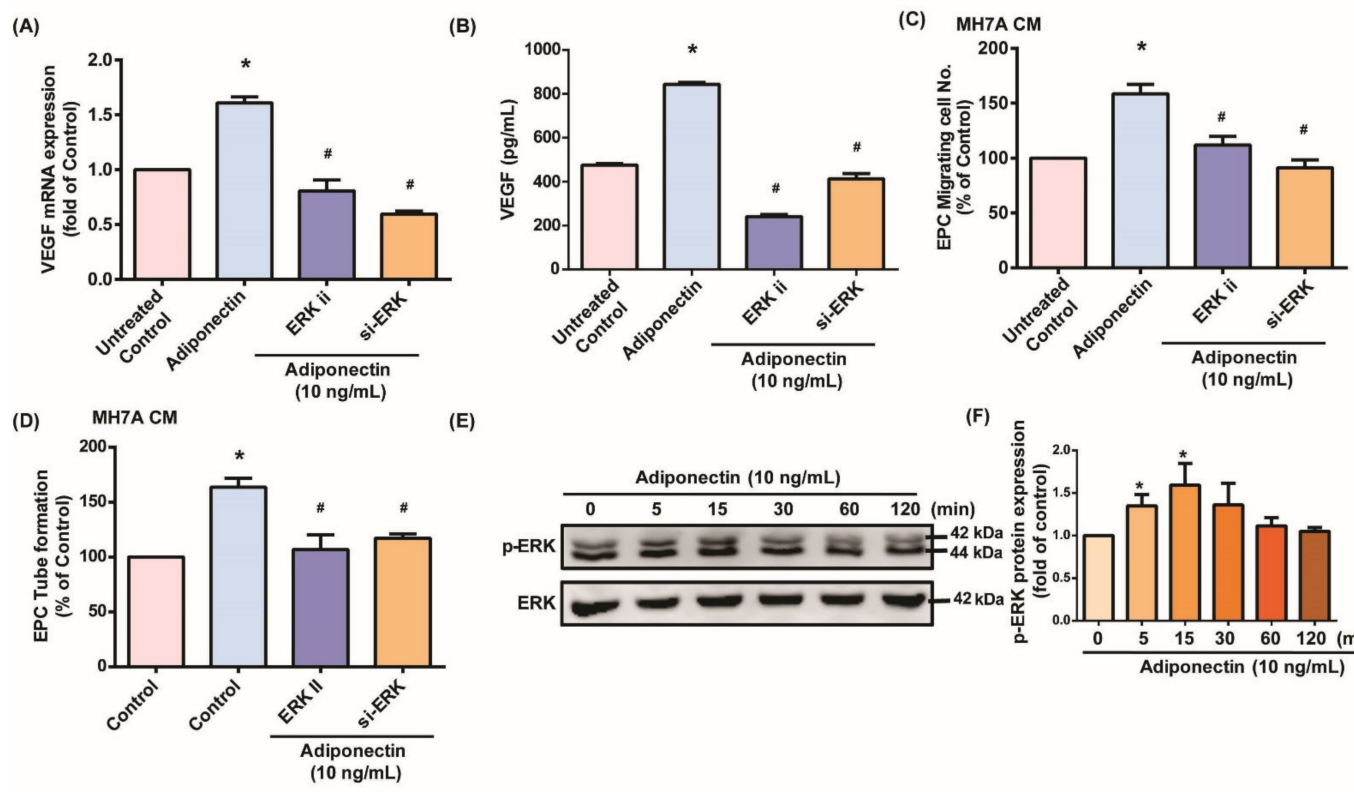

(E)

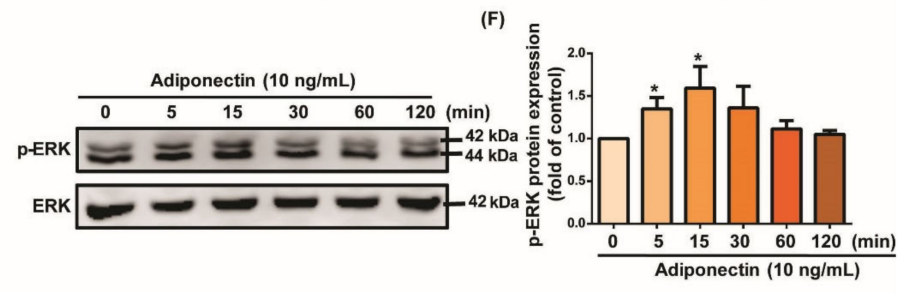

Figure 4. The ERK signaling pathway is essential in adiponectin-stimulated EPC migration and tube formation. (A,B) MH7A cells were left untreated, stimulated with adiponectin $(10 \mathrm{ng} / \mathrm{mL})$ alone for $24 \mathrm{~h}$, or pretreated with ERK inhibitors (ERK II) or transfected with ERK siRNA for $30 \mathrm{~min}$, prior to $24 \mathrm{~h}$ of adiponectin $(10 \mathrm{ng} / \mathrm{mL})$ stimulation. VEGF expression was examined by qPCR and ELISA assays ( $n=4$ per group). (C,D) Collected CM from MH7A was applied to EPCs and angiogenesis was examined by the Transwell and tube formation assays ( $n=5$ per group). (E) MH7A cells were treated with adiponectin for varying amounts of time and Western blot $(n=3)$ determined ERK phosphorylation. (F) Densitometry analysis of (E). ${ }^{*} p<0.05$ versus the control group; ${ }^{*} p<0.05$ versus the adiponectin-treated group. 


\subsection{Adiponectin Enhanced VEGF-Dependent Angiogenesis via Downregulation of} Adiponectin-Mediated miR-106a-5p Expression

Associations between miRNA expression and RA pathogenesis have been mentioned previously [44], although how miRNAs might mediate RA disease during adiponectin administration is unclear. Our analysis of the miRNA prediction algorithms RNAhybrid, miRmap, miRWalk, and TargetScan identified miR-106a-5p as a candidate miRNA capable of binding to the VEGF $3^{\prime}$-UTR region. Adiponectin treatment of MH7A cells caused concentration-dependent decreases in miR-106a-5p expression (Figure 5A). Transfecting the cells with the miR-106a-5p mimic effectively mitigated adiponectin-induced VEGF production (Figure 5B-D), EPC tube growth, and EPC migratory activities (Figure 5E,F). WT-and MT-VEGF $3^{\prime}$-UTR luciferase plasmids were constructed to check whether adiponectin mediated effects decrease the targeting of miR-106a-5p to VEGF $3^{\prime}$-UTRs (Figure 5G). Whereas WT-VEGF $3^{\prime}$-UTR plasmids displayed adiponectin-induced increases in luciferase activity, this phenomenon did not occur in MT-VEGF 3'-UTRs (Figure 5H,I). MiR-106a-5p mimic reversed adiponectin-stimulated luciferase activity (Figure $5 \mathrm{H}, \mathrm{I}$ ), and incubation with MEK and ERK inhibitors blocked adiponectin from downregulating miR-106a-5p (Figure 5J). These data suggest that adiponectin stimulates angiogenic factor production by lowering miR-106a-5p levels via the MEK and ERK signaling cascades.

(A)

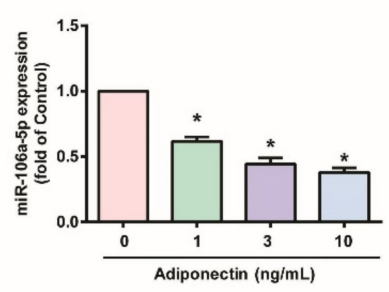

(E)

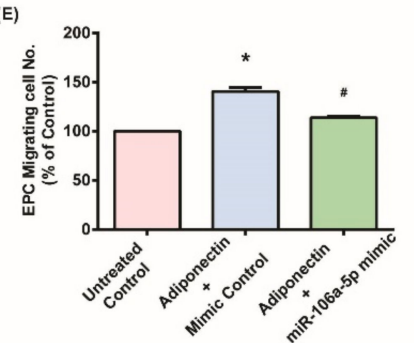

(H)

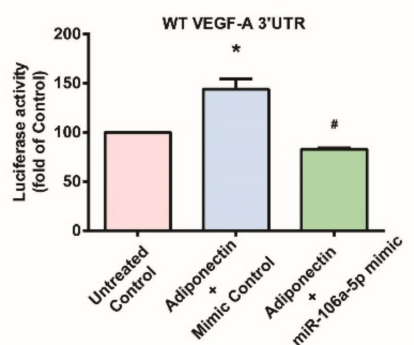

(B)
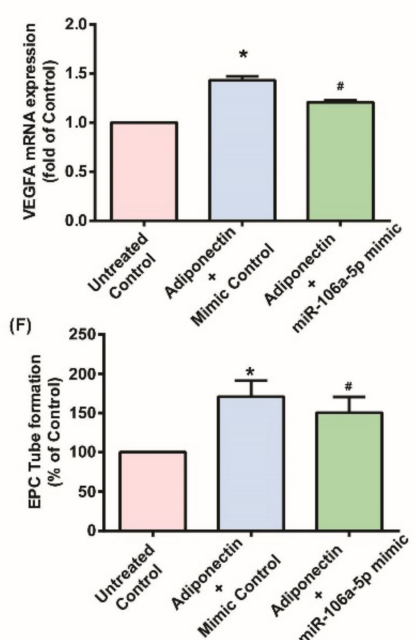

(I)

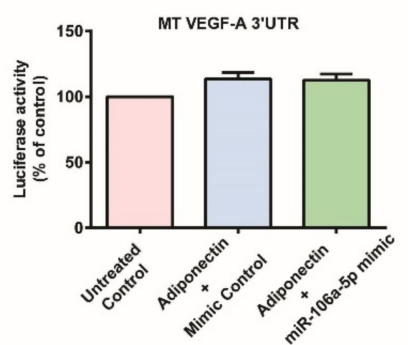

(C)

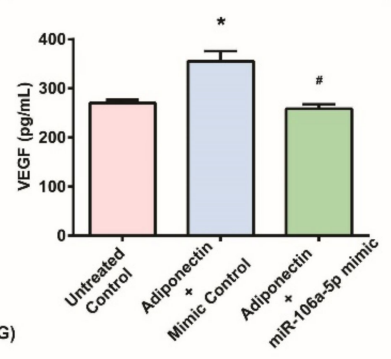

(D)

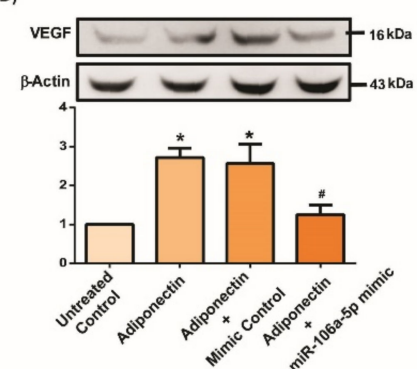

TCTGCCAGAGCACTTTGGGTCC WT VEGF-A 3'UTR GACGUGACAUUCGUGAAAC miR-106a-5p TCTGCGGCAGAGTGATTTGGGTCC MT VEGF-A 3'UTR

Figure 5. Adiponectin enhances VEGF-dependent angiogenesis via the suppression of miR-106a-5p. (A) MH7A cells were incubated with various concentrations adiponectin for $24 \mathrm{~h}$. miR-106a-5p expression was determined by the qPCR assay. (B-D) MH7A cells were transfected with mimic control or miR-106a-5p mimic for $24 \mathrm{~h}$, then stimulated with adiponectin for $24 \mathrm{~h}$. VEGF levels were determined by qPCR, ELISA, and Western blot assay $(n=4)$. (E,F) Collected CM was applied to EPCs and EPC angiogenesis was quantified. (G) Schematic 3'UTR representation of human VEGF containing the miR-106a-5p binding site. (H,I) MH7A cells were transfected with the indicated luciferase plasmid with or without miR-106a-5p mimic for $24 \mathrm{~h}$, then stimulated with adiponectin for $24 \mathrm{~h}$. Relative luciferase activity was determined. (J) MH7A cells were pretreated with MEK or ERK inhibitors for $30 \mathrm{~min}$, then stimulated with adiponectin for $24 \mathrm{~h}$. miR-106a-5p expression was quantified by qPCR. ${ }^{*} p<0.05$ versus the control group; ${ }^{\#} p<0.05$ versus the adiponectin-treated group. 


\subsection{Suppressing Adiponectin Reduces RA Angiogenesis}

In vivo CAM and Matrigel plug experiments examined the angiogenic effects of adiponectin in RA disease. When we transfected adiponectin shRNA into MH7A cells, we observed decreases in adiponectin and VEGF expression (Figure 6A,B). Transfection of the cells with adiponectin shRNA downregulated EPC tube formation and migration, which was reversed by the addition of VEGF (Figure 6C,D). Knockdown of adiponectin attenuated microvasculature development in Matrigel plugs, evaluated by staining with VEGF, CD31, CD34, and CD133 (Figure 6E). Similarly, blood vessel formation in the CAM assay was suppressed by adiponectin shRNA (Figure 6F). These preclinical data confirm that suppression of adiponectin reduces angiogenesis in RA synovial fibroblasts.

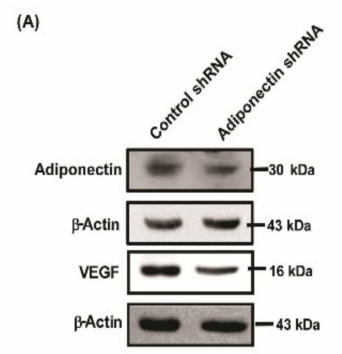

(D)

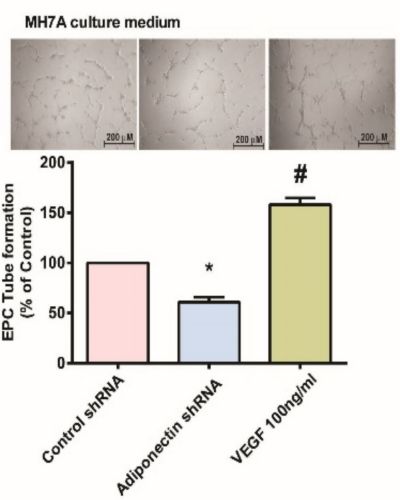

(B)

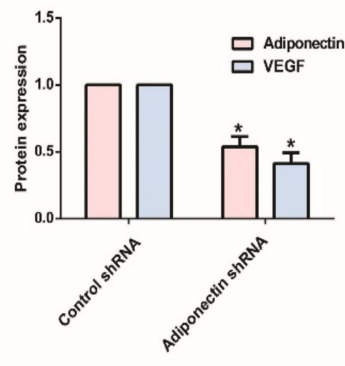

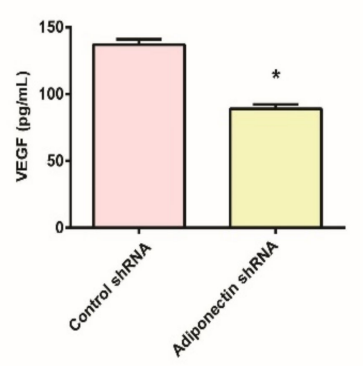

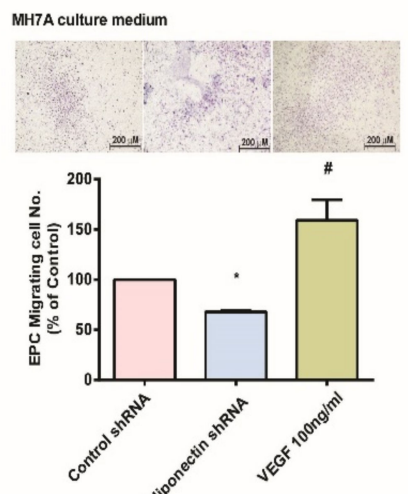

(E)
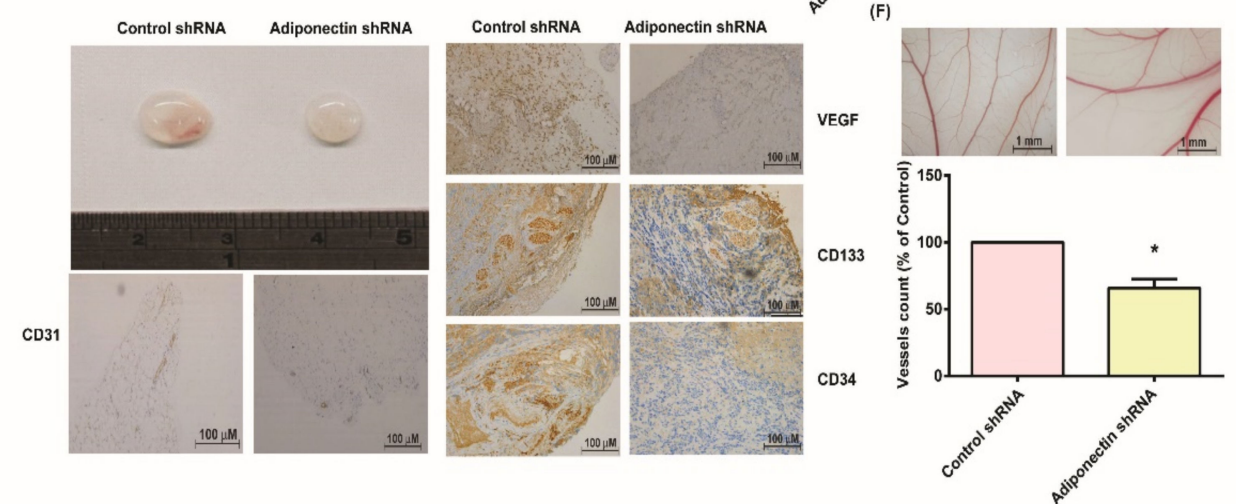

Figure 6. Blocking adiponectin attenuates RA angiogenesis in vivo. (A,B) MH7A cells were infected with adiponectin shRNA for $24 \mathrm{~h}$. Adiponectin and VEGF expression was examined by Western blot $(n=4)$ and ELISA $(n=4)$. (C,D) Collected $\mathrm{CM}$ was applied to EPCs and EPC angiogenesis was quantified. (E) Matrigel plugs containing the harvested CM were subcutaneously injected into the flanks of nude mice. After 7 days, the plugs were photographed and hemoglobin levels were quantified. Plug specimens were immunostained with CD31 $(n=6)$, CD34 $(n=6)$, and CD133 $(n=6)$ antibodies. (F) After subjecting MH7A cells to the treatment conditions as indicated, the harvested CM was applied to 5-day-old fertilized chick embryos for 3 days. CAMs were examined by microscopy and photographed $(n=6)$, and vessels were counted manually. ${ }^{*} p<0.05$ versus the control group; ${ }^{\#} p<0.05$ versus the adiponectin shRNA-transfected group.

\subsection{Attenuating Bone Damage and Angiogenesis by Targeting Adiponectin in CIA Mice}

We sought to determine whether blocking adiponectin would attenuate destructive synovitis in CIA mice. Lentiviral adiponectin shRNA injections significantly reduced hind paw swelling in CIA mice compared with control mice (Figure 7A,B). Micro-CT imaging revealed worse bone erosion of hind paws in CIA mice without additional treatment, whereas the mice infected with lentiviral adiponectin shRNA had less bone damage with higher bone mineral density, bone volume, and trabecular numbers (Figure 7A,C-E). Serum VEGF expression was also decreased in adiponectin shRNA-treated CIA mice (Figure 7F). Intra-articular cartilage damage according to pathologic examination (Figure 7G) revealed significantly increased expression of EPC and angiogenesis vessel markers in the CIA mice, 
versus significant reductions in the adiponectin shRNA treatment group (Figure 7H). Thus, lentiviral adiponectin shRNA administration appears to protect against bone damage and reduce angiogenesis in an RA animal model.

(A)
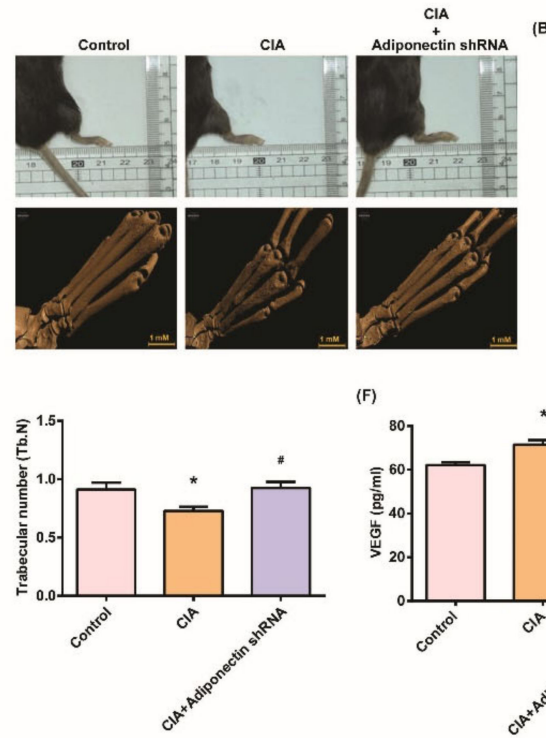

(F)

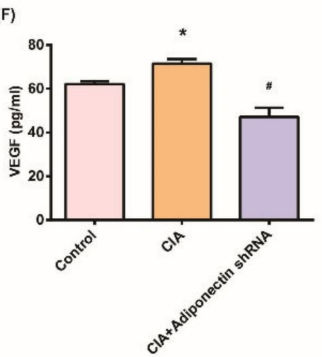

(B)

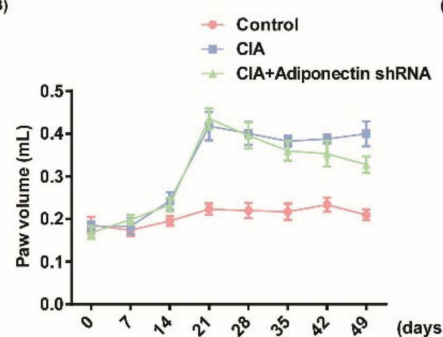

(G)
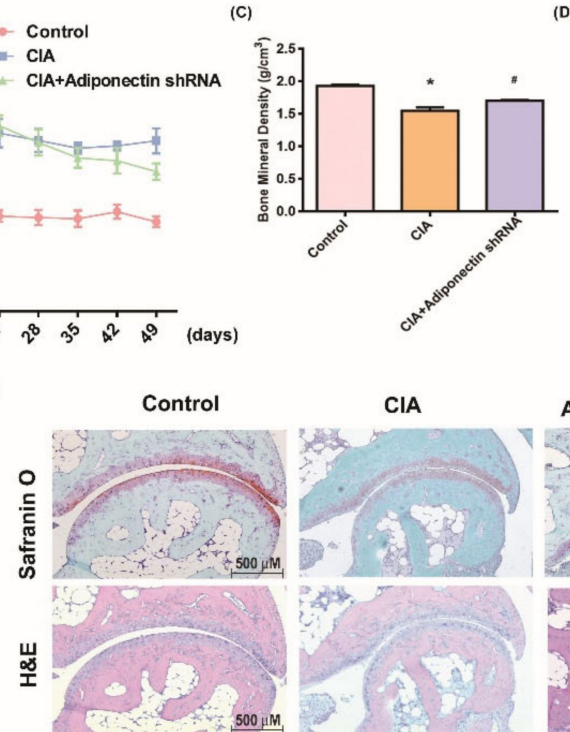

CIA

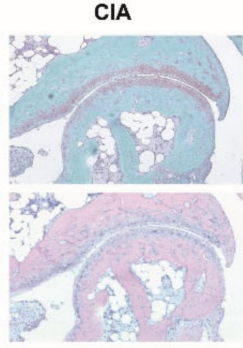

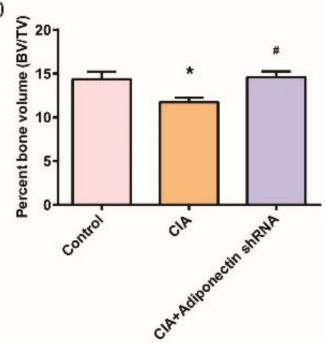

CIA

CIA

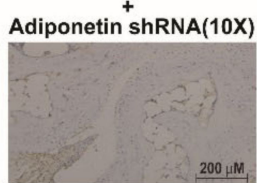

Adiponectin shRNA
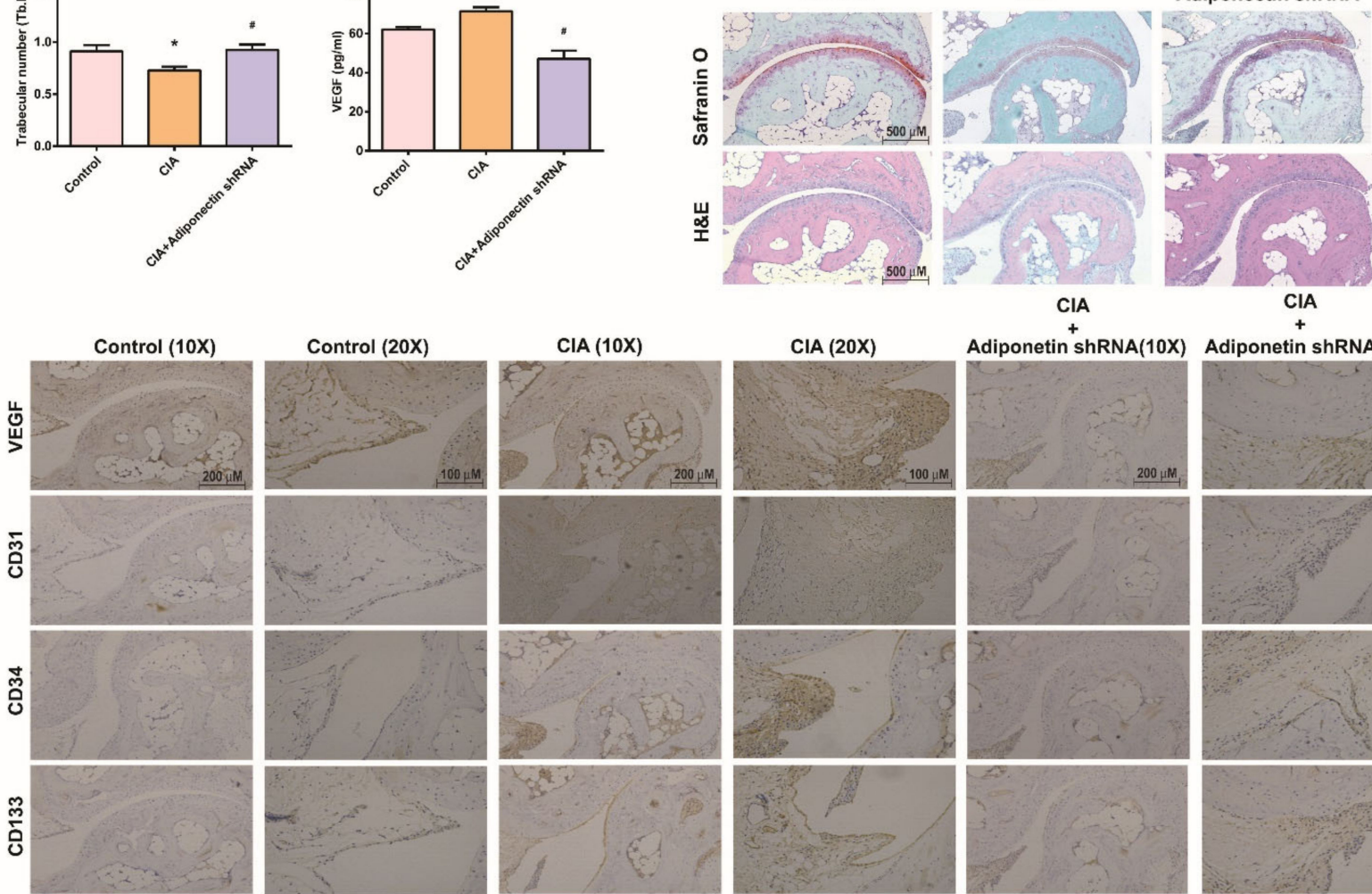

CIA
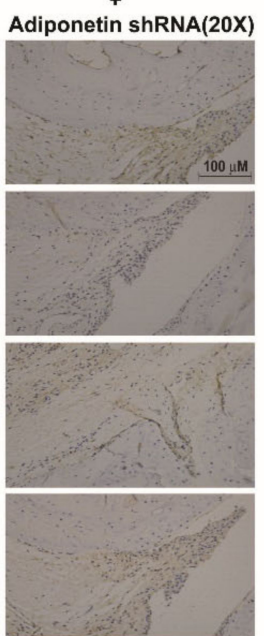

Figure 7. Lentivirus carrying adiponectin short hairpin RNA (sh-adiponectin) reduces bone erosion and angiogenic expression in a CIA model. (A,B) CIA mice received intra-articular injections of $7.1 \times 10^{6}$ PFU adiponectin shRNA on day 14 and were euthanized on day 49. Hind paw swelling was photographed and measured with a digital plethysmometer in the different groups (Control, CIA, and CIA mice receiving intra-articular lentiviral sh-adiponectin; $n=8$ per group). Representative micro-CT images of the hind paws were recorded on Day 56. (C-F) Micro-CT SkyScan Software quantified bone mineral density (BMD), bone volume percentage (BV/TV), and trabecular numbers (Tb. N.). VEGF serum levels were determined by ELISA. $(\mathbf{G}, \mathbf{H})$ Histological sections of ankle joints were stained with H\&E or Safranin O and immunostained with CD31, CD34, and CD133. ${ }^{*} p<0.05$ versus the control group; ${ }^{\#} p<0.05$ versus the untreated CIA group.

\section{Discussion}

RA synovial fibroblasts secrete various proinflammatory cytokines that contribute to surrounding cartilage and bone damage [45]. During the development of RA disease, angiogenesis facilitates oxygen and nutrient transportation to $\mathrm{B}$ cells, $\mathrm{T}$ cells, or macrophages in the inflamed site and propagates the inflamed synovium with immune cell infiltration [3]. RA clinical studies using musculoskeletal ultrasound have shown that subclinical synovitis detected by power Doppler sonography is associated with bone damage [46] and that 
sonographic signals of hypervascularity correlate with angiogenic VEGF levels [47]. Thus, inhibiting neovascularization might further ameliorate RA severity in treatment-refractory patients [48]. We are the first research group to describe how adiponectin promotes angiogenic activities in RA via MEK/ERK signaling and by downregulating miR-106a-5p. Knockdown of adiponectin appears to attenuate synovitis severity and destruction of bone in CIA animal experiments.

Adipokines act as biologically active substances in neuroendocrine-immune interactions. Adipokine synthesis in the joint microenvironment can occur through the activities of synoviocytes, osteoblasts and osteoclasts, chondrocytes, and inflammatory cells [49]. Most of these adipokines, including adiponectin, visfatin, resistin, and leptin, display proinflammatory effects in rheumatic joint disorders. Adiponectin plasma levels positively correlate with RA disease activity $[8,9,50]$. Adiponectin stimulates the expression of various proinflammatory cytokines in RA synovial fibroblasts [51], although the effects of adiponectin on EPC angiogenesis in RA have not been reported previously. It is established that adiponectin increases VEGF secretion in RA synovial fibroblasts and osteoblasts [12-14] and upregulates the expression of endocan, an angiogenic proteoglycan, in synovial fibroblasts $[15,52]$. Our data detail how adiponectin increases VEGF production in RA synovial fibroblasts and EPC angiogenesis via intracellular signal pathways.

Various proangiogenic factors, including VEGF, fibroblast growth factor, and PDGF, are involved in the angiogenic processes of several different diseases, including arthritis [53], and may interfere with the basal levels of EPC tube formation. Incubation of MH7A cells with adiponectin concentration-dependently promotes VEGF synthesis, resulting in EPC angiogenesis. Interestingly, we found that VEGF antibody significantly antagonized increases in EPC angiogenesis induced by adiponectin, when we stimulated MH7A cells for $24 \mathrm{~h}$ in CM. This suggests that VEGF is a vital modulator in EPC-mediated angiogenesis during RA development.

RA angiogenesis is driven by proinflammatory cytokines and proangiogenic mediators released from adjacent tissues or the systemic circulation [3]. Recent observations report that CCL28 and CCR10 expression is upregulated in RA synovial tissue and synovial fluid and that RA angiogenesis is promoted by joint CCL28, which activates the ERK pathway [54]. Another study has revealed that silencing of granzyme B gene expression protects against RA articular injury by suppressing inflammatory and angiogenic factors (VEGF and basic fibroblast growth factor) through the MEK/ERK signaling pathway [55]. Our results indicate that adiponectin induces VEGF-dependent angiogenesis in RA synovial fibroblasts via the MEK/ERK intracellular pathway.

MiRNAs appear to be pivotal regulators of biological functions and pathological illnesses [56]. Altered miRNA expression leads to immune dysregulation, inflammation, or cellular proliferation in RA [54]. In particular, miR-106a-5p participates in the proliferative, invasive, and metastatic behaviors of numerous cancers [57-59]. One OA study has revealed that cryptotanshinone, a Salvia miltiorrhiza Bunge root extract, protects cartilage against degeneration via the miR-106a-5p/GLI-similar 3 (GLIS3) axis [60]. MiR-106a-5p expression was downregulated in human OA cartilage, whereas GLIS3 expression was upregulated [60]. In another study, long non-coding RNA H19 regulated proliferation and apoptosis of OA chondrocytes by modulating miR-106a-5p expression [61]. In our study, adiponectin promoted EPC tube formation and migration by suppressing miR-106a-5p expression in RA.

In CIA animal models, intra-articular adiponectin administration attenuates arthritis by downregulating IL-1, MMP-3, and TNF- $\alpha$ expression in inflamed joints $[62,63]$. Conversely, other studies demonstrate that adiponectin exacerbates CIA by promoting Th17 and receptor activator of nuclear factor- $\mathrm{kB}$ ligand (RANKL) expression [64], or by upregulating osteopontin [65]. Furthermore, although systemic delivery of adiponectin by adenovirus vectors can mitigate CIA disease [66], rheumatic symptoms in CIA were markedly attenuated by administration of monoclonal antibodies against adiponectin isomers [67]. Thus, 
adiponectin may be characterized by proinflammatory or anti-inflammatory effects in RA, depending on the isoforms, exposure time, concentrations, or the microenvironment $[51,68]$.

\section{Conclusions}

More investigation is called for to clarify the interactions between adiponectin and RA. Our data prove that a link exists between adiponectin and EPC angiogenic activities in MH7A cells. This process is VEGF-dependent and regulated by MEK/ERK and miR106a-5p. Our CIA mouse experiments demonstrate that blocking adiponectin significantly ameliorates RA severity. Thus, targeting adiponectin holds promise in the treatment of RA and deserves to be investigated clinically (Figure 8).

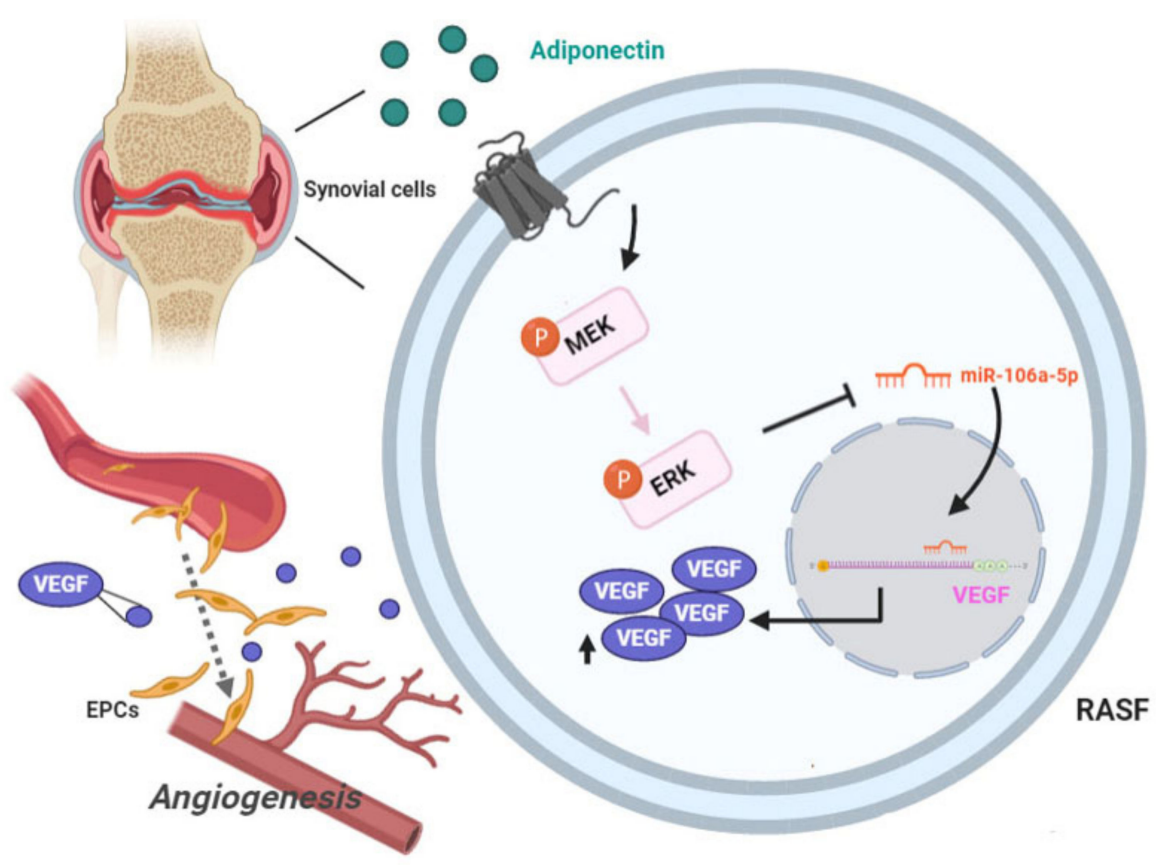

Figure 8. The schematic diagram summarizes the mechanism whereby adiponectin upregulates VEGF expression in MH7A cells. Adiponectin induces VEGF expression and angiogenesis through the MEK/ERK signaling cascade and reduces miR-106-5p expression in MH7A cells.

Author Contributions: C.-C.H.: Methodology, Resources, Writing-Original, draft investigation. Y.-Y.L.: Data curation, draft investigation. S.-C.L.: Methodology, Data curation, Results/experiments, Writing-Original draft. S.-L.H.: Data curation, Methodology. J.-A.L.: Resources, investigation. C.-J.C.: Resources, investigation. S.-W.W.: Data curation, Methodology. C.-H.T.: Project administration, Writing-Review. All authors have read and agreed to the published version of the manuscript.

Funding: This work was supported by grants from the Ministry of Science and Technology in Taiwan (MOST 110-2320-B-039-022-MY3; MOST 110-2314-B-039-008; MOST 110-2314-B-039-012), China Medical University (CMU-110-MF-09), China Medical University Beigang Hospital (110CMUBHR07) and China Medical University Hospital (DMR-110-022).

Institutional Review Board Statement: All experiments involving human clinical samples were approved by the Institutional Review Board of China Medical University Hospital, which granted approval for this study to proceed (Approval no. CMUH108-REC3-039). All experiments involving animals were conducted according to the ethical policies and procedures issued by the Institutional Animal Care and Use Committee of China Medical University, which approved our experiments (Approval no. 2018-102).

Informed Consent Statement: Informed consent was obtained from all subjects involved in the study.

Data Availability Statement: The data presented in this study are available on request from the corresponding author. 
Acknowledgments: We would like to thank Iona J. MacDonald from China Medical University for her editing of this manuscript.

Conflicts of Interest: The authors declare no conflict of interest.

\section{References}

1. Smolen, J.S.; Aletaha, D.; McInnes, I.B. Rheumatoid arthritis. Lancet 2016, 388, 2023-2038. [CrossRef]

2. Koch, A.E. Review: Angiogenesis: Implications for rheumatoid arthritis. Arthritis Rheum. 1998, 41, 951-962. [CrossRef]

3. Elshabrawy, H.A.; Chen, Z.; Volin, M.V.; Ravella, S.; Virupannavar, S.; Shahrara, S. The pathogenic role of angiogenesis in rheumatoid arthritis. Angiogenesis 2015, 18, 433-448. [CrossRef]

4. Wang, Y.; Da, G.; Li, H.; Zheng, Y. Avastin exhibits therapeutic effects on collagen-induced arthritis in rat model. Inflammation 2013, 36, 1460-1467. [CrossRef]

5. Sun, Y.; Xun, K.; Wang, C.; Zhao, H.; Bi, H.; Chen, X.; Wang, Y. Adiponectin, an unlocking adipocytokine. Cardiovasc. Ther. 2009, 27, 59-75. [CrossRef] [PubMed]

6. Liu, M.; Liu, F. Regulation of adiponectin multimerization, signaling and function. Best Pract. Res. Clin. Endocrinol. Metab. 2014, 28, 25-31. [CrossRef] [PubMed]

7. Luo, Y.; Liu, M. Adiponectin: A versatile player of innate immunity. J. Mol. Cell Biol. 2016, 8, 120-128. [CrossRef] [PubMed]

8. Giles, J.T.; Allison, M.; Bingham, C.O., III; Scott, W.M., Jr.; Bathon, J.M. Adiponectin is a mediator of the inverse association of adiposity with radiographic damage in rheumatoid arthritis. Arthritis Rheum. 2009, 61, 1248-1256. [CrossRef] [PubMed]

9. Rho, Y.H.; Solus, J.; Sokka, T.; Oeser, A.; Chung, C.P.; Gebretsadik, T.; Shintani, A.; Pincus, T.; Stein, C.M. Adipocytokines are associated with radiographic joint damage in rheumatoid arthritis. Arthritis Rheum. 2009, 60, 1906-1914. [CrossRef] [PubMed]

10. Chen, X.; Lu, J.; Bao, J.; Guo, J.; Shi, J.; Wang, Y. Adiponectin: A biomarker for rheumatoid arthritis? Cytokine Growth Factor Rev. 2013, 24, 83-89. [CrossRef]

11. Scotece, M.; Conde, J.; Vuolteenaho, K.; Koskinen, A.; López, V.; Gómez-Reino, J.; Lago, F.; Moilanen, E.; Gualillo, O. Adipokines as drug targets in joint and bone disease. Drug Discov. Today 2014, 19, 241-258. [CrossRef]

12. Choi, H.M.; Lee, Y.A.; Lee, S.H.; Hong, S.J.; Hahm, D.H.; Choi, S.Y.; Yang, H.I.; Yoo, M.C.; Kim, K.S. Adiponectin may contribute to synovitis and joint destruction in rheumatoid arthritis by stimulating vascular endothelial growth factor, matrix metalloproteinase1 , and matrix metalloproteinase-13 expression in fibroblast-like synoviocytes more than proinflammatory mediators. Arthritis Res. Ther. 2009, 11, R161.

13. Lee, Y.A.; Choi, H.M.; Lee, S.H.; Yang, H.I.; Yoo, M.C.; Hong, S.J.; Kim, K.S. Synergy between adiponectin and interleukin-1 $\beta$ on the expression of interleukin-6, interleukin-8, and cyclooxygenase-2 in fibroblast-like synoviocytes. Exp. Mol. Med. 2012, 44, 440-447. [CrossRef]

14. Lee, Y.A.; Ji, H.I.; Lee, S.H.; Hong, S.J.; Yang, H.I.; Chul Yoo, M.; Kim, K.S. The role of adiponectin in the production of IL-6, IL-8, VEGF and MMPs in human endothelial cells and osteoblasts: Implications for arthritic joints. Exp. Mol. Med. 2014, 46, e72. [CrossRef]

15. Kim, K.S.; Lee, Y.A.; Ji, H.I.; Song, R.; Kim, J.Y.; Lee, S.H.; Hong, S.J.; Yoo, M.C.; Yang, H.I. Increased expression of endocan in arthritic synovial tissues: Effects of adiponectin on the expression of endocan in fibroblast-like synoviocytes. Mol. Med. Rep. 2015, 11, 2695-2702. [CrossRef]

16. Asahara, T.; Murohara, T.; Sullivan, A.; Silver, M.; van der Zee, R.; Li, T.; Witzenbichler, B.; Schatteman, G.; Isner, J.M. Isolation of putative progenitor endothelial cells for angiogenesis. Science 1997, 275, 964-967. [CrossRef] [PubMed]

17. Fadini, G.P.; Losordo, D.; Dimmeler, S. Critical reevaluation of endothelial progenitor cell phenotypes for therapeutic and diagnostic use. Circ. Res. 2012, 110, 624-637. [CrossRef] [PubMed]

18. Rüger, B.; Giurea, A.; Wanivenhaus, A.H.; Zehetgruber, H.; Hollemann, D.; Yanagida, G.; Groger, M.; Petzelbauer, P.; Smolen, J.S.; Hoecker, P.; et al. Endothelial precursor cells in the synovial tissue of patients with rheumatoid arthritis and osteoarthritis. Arthritis Rheum. 2004, 50, 2157-2166. [CrossRef] [PubMed]

19. De Villeroché, V.J.; Avouac, J.; Ponceau, A.; Ruiz, B.; Kahan, A.; Boileau, C.; Uzan, G.; Allanore, Y. Enhanced late-outgrowth circulating endothelial progenitor cell levels in rheumatoid arthritis and correlation with disease activity. Arthritis Res. Ther. 2010, 12, R27. [CrossRef]

20. Bartel, D.P. MicroRNAs: Genomics, biogenesis, mechanism, and function. Cell 2004, 116, 281-297. [CrossRef]

21. Mousavi, M.J.; Jamshidi, A.; Chopra, A.; Aslani, S.; Akhlaghi, M.; Mahmoudi, M. Implications of the noncoding RNAs in rheumatoid arthritis pathogenesis. J. Cell Physiol. 2018, 234, 335-347. [CrossRef]

22. Chen, X.M.; Huang, Q.C.; Yang, S.L.; Chu, Y.L.; Yan, Y.H.; Han, L.; Huang, Y.; Huang, R.Y. Role of Micro RNAs in the Pathogenesis of Rheumatoid Arthritis: Novel Perspectives Based on Review of the Literature. Medicine 2015, 94, e1326. [CrossRef]

23. Al-Rawaf, H.A. Circulating microRNAs and adipokines as markers of metabolic syndrome in adolescents with obesity. Clin. Nutr. 2019, 38, 2231-2238. [CrossRef]

24. Santovito, D.; De Nardis, V.; Marcantonio, P.; Mandolini, C.; Paganelli, C.; Vitale, E.; Buttitta, F.; Bucci, M.; Mezzetti, A.; Consoli, A.; et al. Plasma exosome microRNA profiling unravels a new potential modulator of adiponectin pathway in diabetes: Effect of glycemic control. J. Clin. Endocrinol. Metab. 2014, 99, E1681-E1685. [CrossRef]

25. Lei, L.; Zhou, C.; Yang, X.; Li, L. Down-regulation of microRNA-375 regulates adipokines and inhibits inflammatory cytokines by targeting AdipoR2 in non-alcoholic fatty liver disease. Clin. Exp. Pharmacol. Physiol. 2018, 45, 819-831. [CrossRef] 
26. Huang, C.Y.; Chang, A.C.; Chen, H.T.; Wang, S.W.; Lo, Y.S.; Tang, C.H. Adiponectin promotes VEGF-C-dependent lymphangiogenesis by inhibiting miR-27b through a CaMKII/AMPK/p38 signaling pathway in human chondrosarcoma cells. Clin. Sci. 2016, 130, 1523-1533. [CrossRef] [PubMed]

27. Hu, S.L.; Chang, A.C.; Huang, C.C.; Tsai, C.H.; Lin, C.C.; Tang, C.H. Myostatin Promotes Interleukin-1 $\beta$ Expression in Rheumatoid Arthritis Synovial Fibroblasts through Inhibition of miR-21-5p. Front. Immunol. 2017, 8, 1747. [CrossRef] [PubMed]

28. Lee, H.-P.; Wu, Y.-C.; Chen, B.-C.; Liu, S.-C.; Li, T.-M.; Huang, W.-C.; Hsu, C.-J.; Tang, C.-H. Soya-cerebroside reduces interleukin production in human rheumatoid arthritis synovial fibroblasts by inhibiting the ERK, NF-KB and AP-1 signalling pathways. Food Agric. Immunol. 2020, 31, 740-750. [CrossRef]

29. Lee, H.-P.; Chen, P.-C.; Wang, S.-W.; Fong, Y.-C.; Tsai, C.-H.; Tsai, F.-J.; Chung, J.-G.; Huang, C.-Y.; Yang, J.-S.; Hsu, Y.-M.; et al. Plumbagin suppresses endothelial progenitor cell-related angiogenesis in vitro and In Vivo. J. Funct. Foods 2019, 52, 537-544. [CrossRef]

30. Lee, H.-P.; Wang, S.-W.; Wu, Y.-C.; Tsai, C.-H.; Tsai, F.-J.; Chung, J.-G.; Huang, C.-Y.; Yang, J.-S.; Hsu, Y.-M.; Yin, M.-C.; et al. Glucocerebroside reduces endothelial progenitor cell-induced angiogenesis. Food Agric. Immunol. 2019, 30, 1033-1045. [CrossRef]

31. Lee, H.-P.; Wang, S.-W.; Wu, Y.-C.; Lin, L.-W.; Tsai, F.-J.; Yang, J.-S.; Li, T.-M.; Tang, C.-H. Soya-cerebroside inhibits VEGF-facilitated angiogenesis in endothelial progenitor cells. Food Agric. Immunol. 2020, 31, 193-204. [CrossRef]

32. Liu, S.C.; Chiu, C.P.; Tsai, C.H.; Hung, C.Y.; Li, T.M.; Wu, Y.C.; Tang, C.H. Soya-cerebroside, an extract of Cordyceps militaris, suppresses monocyte migration and prevents cartilage degradation in inflammatory animal models. Sci. Rep. 2017, 7, 43205. [CrossRef] [PubMed]

33. Liu, S.-C.; Tsai, C.-H.; Wu, T.-Y.; Tsai, C.-H.; Tsai, F.-J.; Chung, J.-G.; Huang, C.-Y.; Yang, J.-S.; Hsu, Y.-M.; Yin, M.-C.; et al. Soya-cerebroside reduces IL-1 $\beta$-induced MMP-1 production in chondrocytes and inhibits cartilage degradation: Implications for the treatment of osteoarthritis. Food Agric. Immunol. 2019, 30, 620-632. [CrossRef]

34. Tang, C.H.; Hsu, C.J.; Fong, Y.C. The CCL5/CCR5 axis promotes interleukin-6 production in human synovial fibroblasts. Arthritis Rheum. 2010, 62, 3615-3624. [CrossRef] [PubMed]

35. Lee, H.-P.; Liu, S.-C.; Wang, Y.-H.; Chen, B.-C.; Chen, H.-T.; Li, T.-M.; Huang, W.-C.; Hsu, C.-J.; Wu, Y.-C.; Tang, C.-H. Cordycerebroside A suppresses VCAM-dependent monocyte adhesion in osteoarthritis synovial fibroblasts by inhibiting MEK/ERK/AP-1 signaling. J. Funct. Foods 2021, 86, 104712. [CrossRef]

36. Su, C.-H.; Lin, C.-Y.; Tsai, C.-H.; Lee, H.-P.; Lo, L.-C.; Huang, W.-C.; Wu, Y.-C.; Hsieh, C.-L.; Tang, C.-H. Betulin suppresses TNF- $\alpha$ and IL-1 $\beta$ production in osteoarthritis synovial fibroblasts by inhibiting the MEK/ERK/NF-kB pathway. J. Funct. Foods 2021, 86, 2411-2502. [CrossRef]

37. Chen, C.Y.; Su, C.M.; Hsu, C.J.; Huang, C.C.; Wang, S.W.; Liu, S.C.; Chen, W.C.; Fuh, L.J.; Tang, C.H. CCN1 Promotes VEGF Production in Osteoblasts and Induces Endothelial Progenitor Cell Angiogenesis by Inhibiting miR-126 Expression in Rheumatoid Arthritis. J. Bone Miner. Res. 2017, 32, 34-45. [CrossRef]

38. Storgard, C.; Mikolon, D.; Stupack, D.G. Angiogenesis assays in the chick CAM. Methods Mol. Biol. 2005, 294, 123-136.

39. Wu, M.H.; Huang, C.Y.; Lin, J.A.; Wang, S.W.; Peng, C.Y.; Cheng, H.C.; Tang, C.H. Endothelin-1 promotes vascular endothelial growth factor-dependent angiogenesis in human chondrosarcoma cells. Oncogene 2014, 33, 1725-1735. [CrossRef]

40. Bäcklund, J.; Li, C.; Jansson, E.; Carlsen, S.; Merky, P.; Nandakumar, K.S.; Haag, S.; Ytterberg, J.; Zubarev, R.A.; Holmdahl, R. C57BL/ 6 mice need MHC class II Aq to develop collagen-induced arthritis dependent on autoreactive T cells. Ann. Rheum. Dis. 2013, 72, 1225-1232. [CrossRef]

41. Kamio, N.; Akifusa, S.; Yamaguchi, N.; Yamashita, Y. Induction of granulocyte colony-stimulating factor by globular adiponectin via the MEK-ERK pathway. Mol. Cell Endocrinol. 2008, 292, 20-25. [CrossRef]

42. Wijesekara, N.; Krishnamurthy, M.; Bhattacharjee, A.; Suhail, A.; Sweeney, G.; Wheeler, M.B. Adiponectin-induced ERK and Akt phosphorylation protects against pancreatic beta cell apoptosis and increases insulin gene expression and secretion. J. Biol. Chem. 2010, 285, 33623-33631. [CrossRef]

43. Luo, L.; Li, J.; Liu, H.; Jian, X.; Zou, Q.; Zhao, Q.; Le, Q.; Chen, H.; Gao, X.; He, C. Adiponectin Is Involved in Connective Tissue Growth Factor-Induced Proliferation, Migration and Overproduction of the Extracellular Matrix in Keloid Fibroblasts. Int. J. Mol. Sci. 2017, 18, 1044. [CrossRef]

44. Liao, Y.Y.; Tsai, H.C.; Chou, P.Y.; Wang, S.W.; Chen, H.T.; Lin, Y.M.; Chiang, I.P.; Chang, T.M.; Hsu, S.K.; Chou, M.C.; et al. CCL3 promotes angiogenesis by dysregulation of miR-374b/VEGF-A axis in human osteosarcoma cells. Oncotarget 2016, 7, 4310-4325. [CrossRef]

45. Bartok, B.; Firestein, G.S. Fibroblast-like synoviocytes: Key effector cells in rheumatoid arthritis. Immunol. Rev. 2010, 233, 233-255. [CrossRef] [PubMed]

46. Kawashiri, S.Y.; Suzuki, T.; Nakashima, Y.; Horai, Y.; Okada, A.; Iwamoto, N.; Ichinose, K.; Tamai, M.; Arima, K.; Nakamura, H.; et al. Ultrasonographic examination of rheumatoid arthritis patients who are free of physical synovitis: Power Doppler subclinical synovitis is associated with bone erosion. Rheumatology 2014, 53, 562-569. [CrossRef]

47. Kitchen, J.; Kane, D. Greyscale and power Doppler ultrasonographic evaluation of normal synovial joints: Correlation with proand anti-inflammatory cytokines and angiogenic factors. Rheumatology 2015, 54, 458-462. [CrossRef]

48. Tas, S.W.; Maracle, C.X.; Balogh, E.; Szekanecz, Z. Targeting of proangiogenic signalling pathways in chronic inflammation. Nat. Rev. Rheumatol. 2016, 12, 111-122. [CrossRef] [PubMed] 
49. Carrion, M.; Frommer, K.W.; Perez-Garcia, S.; Muller-Ladner, U.; Gomariz, R.P.; Neumann, E. The Adipokine Network in Rheumatic Joint Diseases. Int. J. Mol. Sci. 2019, 20, 4091. [CrossRef] [PubMed]

50. Minamino, H.; Katsushima, M.; Yoshida, T.; Hashimoto, M.; Fujita, Y.; Shirakashi, M.; Yamamoto, W.; Murakami, K.; Murata, K.; Nishitani, K.; et al. Increased circulating adiponectin is an independent disease activity marker in patients with rheumatoid arthritis: A cross-sectional study using the KURAMA database. PLoS ONE 2020, 15, e0229998. [CrossRef]

51. Liu, D.; Luo, S.; Li, Z. Multifaceted roles of adiponectin in rheumatoid arthritis. Int. Immunopharmacol. 2015, 28, 1084-1090. [CrossRef]

52. Yang, J.; Yang, Q.; Yu, S.; Zhang, X. Endocan: A new marker for cancer and a target for cancer therapy. Biomed. Rep. 2015, 3, 279-283. [CrossRef]

53. MacDonald, I.J.; Liu, S.C.; Su, C.M.; Wang, Y.H.; Tsai, C.H.; Tang, C.H. Implications of Angiogenesis Involvement in Arthritis. Int . J. Mol. Sci. 2018, 19, 2012. [CrossRef]

54. Tavasolian, F.; Abdollahi, E.; Rezaei, R.; Momtazi-Borojeni, A.A.; Henrotin, Y.; Sahebkar, A. Altered Expression of MicroRNAs in Rheumatoid Arthritis. J. Cell Biochem. 2018, 119, 478-487. [CrossRef]

55. Bao, C.X.; Chen, H.X.; Mou, X.J.; Zhu, X.K.; Zhao, Q.; Wang, X.G. GZMB gene silencing confers protection against synovial tissue hyperplasia and articular cartilage tissue injury in rheumatoid arthritis through the MAPK signaling pathway. Biomed. Pharmacother. 2018, 103, 346-354. [CrossRef] [PubMed]

56. O'Brien, J.; Hayder, H.; Zayed, Y.; Peng, C. Overview of MicroRNA Biogenesis, Mechanisms of Actions, and Circulation. Front. Endocrinol. 2018, 9, 402. [CrossRef]

57. Yue, B.; Sun, B.; Liu, C.; Zhao, S.; Zhang, D.; Yu, F.; Yan, D. Long non-coding RNA Fer-1-like protein 4 suppresses oncogenesis and exhibits prognostic value by associating with miR-106a-5p in colon cancer. Cancer Sci. 2015, 106, 1323-1332. [CrossRef] [PubMed]

58. Hu, B.; Cai, H.; Zheng, R.; Yang, S.; Zhou, Z.; Tu, J. Long non-coding RNA 657 suppresses hepatocellular carcinoma cell growth by acting as a molecular sponge of miR-106a-5p to regulate PTEN expression. Int. J. Biochem. Cell Biol. 2017, 92, 34-42. [CrossRef] [PubMed]

59. Pan, Y.J.; Wei, L.L.; Wu, X.J.; Huo, F.C.; Mou, J.; Pei, D.S. MiR-106a-5p inhibits the cell migration and invasion of renal cell carcinoma through targeting PAK5. Cell Death Dis. 2017, 8, e3155. [CrossRef]

60. Ji, Q.; Qi, D.; Xu, X.; Xu, Y.; Goodman, S.B.; Kang, L.; Song, Q.; Fan, Z.; Maloney, W.J.; Wang, Y. Cryptotanshinone Protects Cartilage against Developing Osteoarthritis through the miR-106a-5p/GLIS3 Axis. Mol. Ther. Nucleic Acids 2018, 11, 170-179. [CrossRef] [PubMed]

61. Zhang, X.; Liu, X.; Ni, X.; Feng, P.; Wang, Y.U. Long non-coding RNA H19 modulates proliferation and apoptosis in osteoarthritis via regulating miR-106a-5p. J. Biosci. 2019, 44, 128. [CrossRef] [PubMed]

62. Lee, S.W.; Kim, J.H.; Park, M.C.; Park, Y.B.; Lee, S.K. Adiponectin mitigates the severity of arthritis in mice with collagen-induced arthritis. Scand. J. Rheumatol. 2008, 37, 260-268. [CrossRef] [PubMed]

63. Wu, D.; Hua, B.; Fang, Z.; Liu, J.; Liu, N.; Ma, Y. Adiponectin exerts a potent anti-arthritic effect and insulin resistance in collagen-induced arthritic rats. Int. J. Rheum. Dis. 2018, 21, 1496-1503. [CrossRef] [PubMed]

64. Sun, X.; Feng, X.; Tan, W.; Lin, N.; Hua, M.; Wei, Y.; Wang, F.; Li, N.; Zhang, M. Adiponectin exacerbates collagen-induced arthritis via enhancing Th17 response and prompting RANKL expression. Sci. Rep. 2015, 5, 11296. [CrossRef] [PubMed]

65. Qian, J.; Xu, L.; Sun, X.; Wang, Y.; Xuan, W.; Zhang, Q.; Zhao, P.; Wu, Q.; Liu, R.; Che, N.; et al. Adiponectin aggravates bone erosion by promoting osteopontin production in synovial tissue of rheumatoid arthritis. Arthritis Res. Ther. 2018, 20, 26. [CrossRef] [PubMed]

66. Ebina, K.; Oshima, K.; Matsuda, M.; Fukuhara, A.; Maeda, K.; Kihara, S.; Hashimoto, J.; Ochi, T.; Banda, N.K.; Yoshikawa, H.; et al. Adenovirus-mediated gene transfer of adiponectin reduces the severity of collagen-induced arthritis in mice. Biochem. Biophys. Res. Commun. 2009, 378, 186-191. [CrossRef]

67. Lee, Y.A.; Hahm, D.H.; Kim, J.Y.; Sur, B.; Lee, H.M.; Ryu, C.J.; Yang, H.I.; Kim, K.S. Potential therapeutic antibodies targeting specific adiponectin isoforms in rheumatoid arthritis. Arthritis Res. Ther. 2018, 20, 245. [CrossRef]

68. Choi, H.M.; Doss, H.M.; Kim, K.S. Multifaceted Physiological Roles of Adiponectin in Inflammation and Diseases. Int. J. Mol. Sci. 2020, 21, 1219. [CrossRef] 